\title{
Development of a local, sustainable and co-designed product of mineral craft for an ASM association: the ITAPORARTE case.
}

\author{
MOL, Adriano A.; Doutor; Universidade do Estado de Minas Gerais \\ adriano.mol@uemg.br
}
GUERRA, Mara L. P.; Mestre; Universidade do Estado de Minas Gerais mara.guerra@uemg.br

TEIXEIRA, M. Bernadete S.; Doutora; Universidade do Estado de Minas Gerais maria.teixeira@uemg.br

\author{
CANAAN, Raquel P.; Doutora; Universidade do Estado de Minas Gerais \\ raquel.pcanaan@gmail.com
}

Palavras chave: sustentabilidade, lapidação, design de joias, artesanato, mineração artesanal

\begin{abstract}
O artigo descreve ações de design voltadas à instalação de um laboratório de campo avançado em uma região que está dentre as mais ricas em recursos minerais e as mais pobres em desenvolvimento social e econômico do Estado de Minas Gerais. O chamado Laboratório Itaporarte foi desenvolvido a partir de 2006 por meio de diferentes projetos integrados por equipes multidisciplinares, como iniciativa de um centro de estudos de uma Universidade estadual, apoiada desde o início por políticas públicas de desenvolvimento tecnológico regional. As ações descritas foram apresentadas como resposta a demanda da comunidade para treinamento voltado à melhorar aspectos de qualidade e sustentabilidade em diferentes níveis da cadeia produtiva de gemas e joias. O objetivo do projeto foi desenvolver novos produtos a partir da riqueza material e imaterial da região, e o resultado foi a criação de uma linha de artesanato mineral contemporâneo que foi posteriormente premiada em concursos de design.
\end{abstract}

Keywords: sustainability, gem cutting, jewelry design, contemporary craft, ASM

The article describes design actions aimed at installing a field laboratory in a region that is at the same time among the richest in mineral resources and the poorest in social and economic development in the State of Minas Gerais. The so-called Itaporarte Laboratory was developed from 2006 onwards through different projects integrated by multidisciplinary teams, as an initiative of a study center located in a state university, which was supported since the beginning by public policies for regional technological development. The actions described here were presented in response to the community's demand for training, aimed at improving aspects of quality and sustainability at different levels of the gem and jewelry production chain. Its objective was to develop new products based on the material and immaterial wealth of the region, and the result was the creation of contemporary mineral handicrafts that were later awarded in design competitions.

\section{Prelude: Origin and Recognition}

The territory known as the Jequitinhonha Valley encompasses one of the largest gemological provinces in the world, located in northeastern Minas Gerais state in Brazil. Although being the poorer region of the state, and one of the poorest in the country, the region has a vast popular culture, as a counterpoint to its many needs. The immaterial heritage of Jequitinhonha can be seen in characteristic arts such as songbooks, well recognized local crafts mostly in ceramics and weaving, in addition to the rich folklore of healers and witchdoctors, from jests to festivals religious. Among the Valley's 80 municipalities, the city of Coronel Murta and its population 
around 10,000 inhabitants, has its economy based on mineral extraction and related to mining activities, predominantly artisanal mining.

The great mineral wealth present there is of valued gemstones tourmaline and beryl, in addition to industrial minerals, such as feldspar and mica. CORNEJO and BARTORELLI (2010) extensively describe the occurrences in the region, with information on all mines and stories about the people involved in its exploration. The authors point to the first discoveries in 1880, but only in 1973 the implementation of a successful tourmaline mining venture in the now famous Barra de Salinas mine.

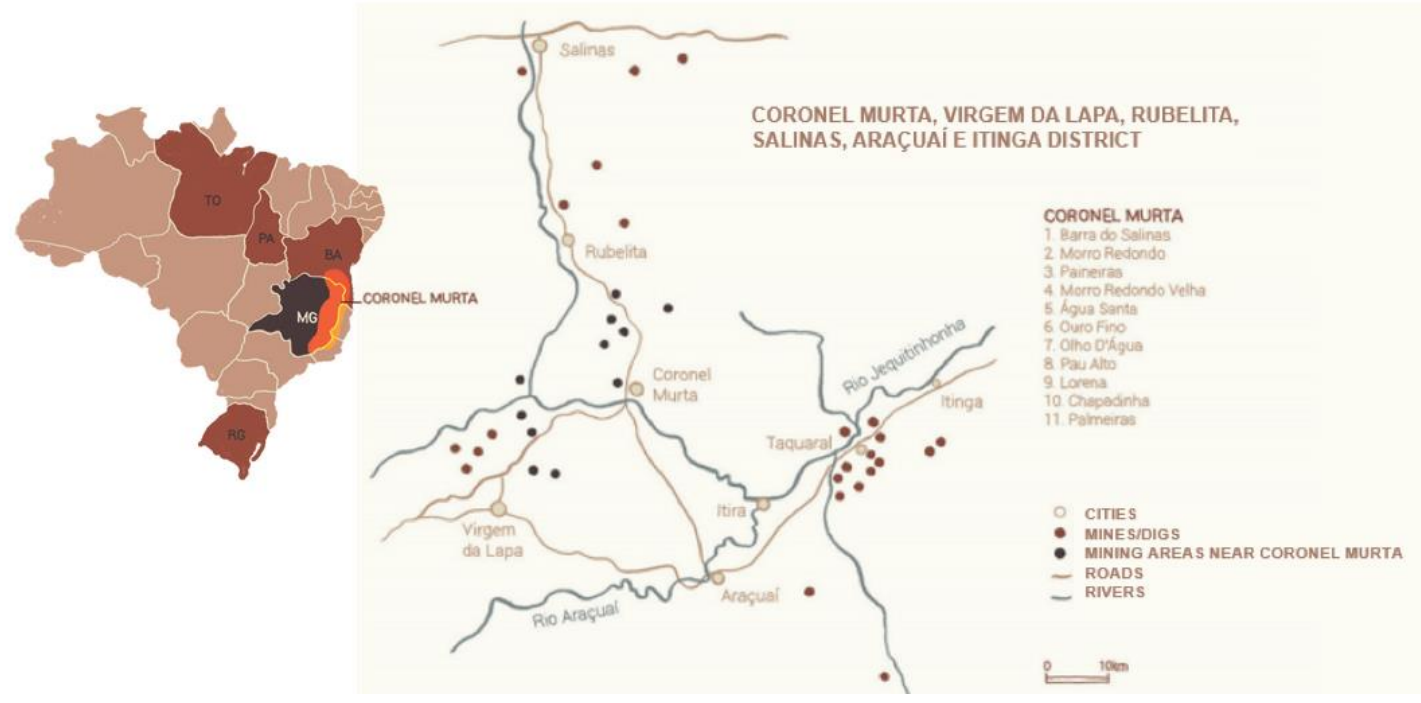

Figure 1: Eastern Brazilian Pegmatitic Province, mostly located in Minas Gerais State in Brazil, and mines around Coronel Murta. Adapted from CORNEJO e BARTORELLI (2010).

Another well-known mine in the region is Morro Redondo, where "tons of bicolor tourmaline" and "the greatest citrine finding of all time" were found in the 1990s. Since then, high-quality pink and green tourmaline has been sold almost entirely for export, for cutting and assembling gold jewelry. On tourmaline exploration, the same authors write:

"During peak production, it is estimated that there were up to four thousand people daily in the digs; most of them, including women and children, were dedicated to digging the tailings discarded by the prospectors, in search of a small stone - an operation called siebagem in their jargon" (CORNEJO and BARTORELLI, 2010).

The main productive pegmatites in the region are distributed about 10 kilometers from the city and produce tourmalines of all colors, from yellowish-green to bluish-green, blue, pink, bicolor (green and pink), tricolor (green, blue and pink), together with other gemstones.

The few products found locally and derived from these resources tended towards a natural acceptance of stereotypes without presenting the same uniqueness and versatility of other productions, as can be seen in ceramic products in the region, for example. The high-end material, suitable for faceting, was nowhere to be seen, due to being mostly exported in rough state. The city did not have a tradition in the production of jewelry or mineral artifacts, and a proposal started to take shape during prospective projects conducted by a cohort of research centers ${ }^{1}$, when possibilities for local development were identified in the region, which did not do justice to the wealth of its land (TEIXEIRA, 2020).

The design team identified an abundance of feldspar and tourmaline gravel available as materials that could be used to add value through the design applied to this local mineral production, geared to the use of this raw, plentiful and readily available material as an alternative for economic and environmental sustainability in mining.

${ }^{1}$ Initially through PROGEMAS, a project that formed an Integrated Action Network for Sustainable Development of the Productive Arrangement of Gems and Jewels in the North/Northeast of Minas Gerais. Led by the Federal University of Minas Gerais/UFMG, Federal University of Ouro Preto/UFOP, and Minas Gerais State University/UEMG, from 20022005. Grant by FINEP- Brazilian Innovation and Research Foundation. 
Coronel Murta has then presented itself as a favorable place to materialize the idea of transforming this underdeveloped material into new products. The credibility of the team was already built and consolidated in its local actions, and was confirmed by the support of social agents, so the city was selected as an ideal place for the proposal of a research and development project by the Center for Studies in Gemstone and Jewelry Design (CEDGEM) of the Design School of the University of the Minas Gerais State (UEMG).

In 2006, this Center proposed the first initiative aiming at employing recognized cultural characteristics of the Jequitinhonha Valley combined with the human potential of the region to develop products within the concept of contemporary crafts, guided by universal trends, but with ballast in the territory of origin.

The starting point of the project was to employ these disposals from mineral extraction, so they could be used in artifacts produced by unskilled labor to be trained through technical and technological training, in the use of appropriate machinery and equipment. Based on these requirements, the project started in late 2006, aiming at installing an experimental production mini-platform in the city, which could later refer to the creation of other production units in the region, suited to specific demands.

The action, however, involved more complex issues at different levels, such as the acquisition of machinery and equipment, as well as finding a suitable and safe place for its installation, that took years to be accomplished instead of the months that were foreseen. It was proven possible, however, to develop a basic technological capacity there, with CEDGEM as an interface unit, supported by the state government and with participation of local public and class representations, the City Hall and the Prospectors Union of Coronel Murta in Middle Jequitinhonha Valley (TEIXEIRA, 2020).

\section{The co-design of mineral craft products}

The realization that the municipality of Coronel Murta did not have a tradition in the development of mineral artifacts opened the possibility of developing products within the concept of "contemporary crafts". Through this aspect, the product to be designed should assimilate contemporary universal trends for products, but to incorporate local elements, such as techniques, materials and the region's own human potential.

During visits its neighboring cities, the amount of material without commercial value caught the team's attention. Some material was to be discarded because of being if little interest to buyers, but looked interesting to be used for value addiction, through a lapidary design perspective. The quantity and variety of feldspar piled up at mine entrances suggested the possibility of specifically working this material into new products. Its appearance, after processing and polishing tests, highlighted nuances ranging from white to brown, sometimes permeated with black tourmaline spots that gave it a differential aspect to be explored (TEIXEIRA, 2020).

The first design concept was a proposition for the use of feldspar rings with surface paintings citing artistic ceramics from Jequitinhonha Valley (Figure 2). This concept materialized the realization that feldspar, discarded in the extraction of gemstones, could be processed into mineral craft objects, in products such as jewelry, costume jewelry and other handicraft objects.

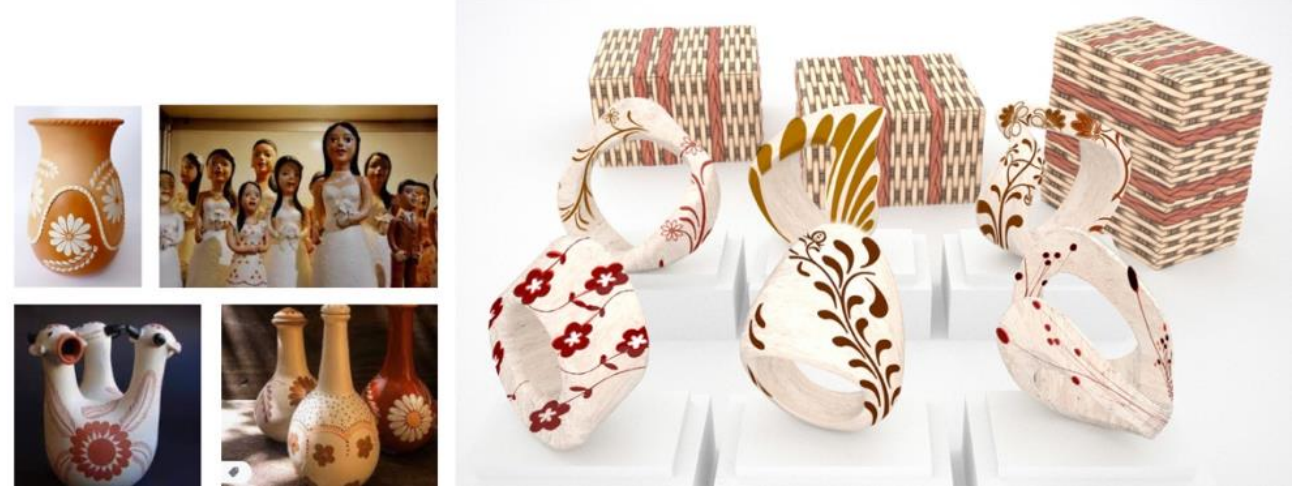

Figure 2: Traditional local Pottery (left) and Initial design concept for Itaporarte products (right) by XAVIER, E. and AMORIM, W., awarded at Brazilian Small Business Service/SEBRAE Design Prize, 2008. 
Together with its initial design exploration, the project went through different parallel phases, such as the research of materials, the assembly of the production nucleus, the training of master craftsmen and the technical qualification of young people in the region, coupled with the graphic design part of the project that looked for an identity and naming for the collective brand of the unit and its products.

For those ideas to take form, it was paramount to delve into the local culture, to recognize the iconography and common signs implicit in the languages of the region's residents, as well as search for the identity elements in old dormant knowledge and techniques. By doing so, another series of formal product trials were developed bringing new local iconographic elements by a second design team, that aimed at improving the feasibility of the initial design concept. Thus, developing artisanal products from feldspar was a process of many ideas imagined under the strong local sun, at the entrances to the mines.
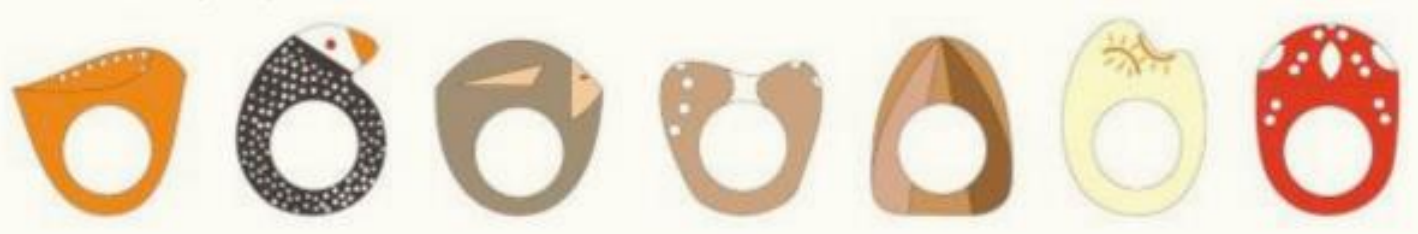

Figure 3: Formal refinement of products based on local iconographic elements. Sketches by GUERRA, M., DINARDI, C. and ROCHA, V.

The study of additional technical possibilities came later, and brought the inlay application of low-grade tourmaline, giving the product its final form. This inlay consists of including small rough tourmalines in the previously prepared feldspar structure, to be then secured in place by epoxy resin. In the end, the whole piece return to the lapping sector and go through the sanding processes, so that the gravels included in the previous step are leveled to the surface until the ring has a smooth surface.
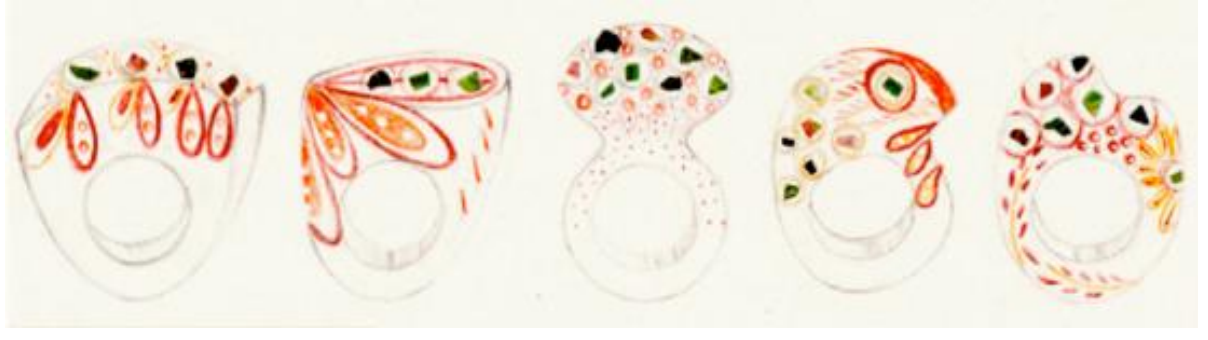

Figure 4: Final iteration of the products, in basic lineup of painted rings with tourmaline inlay. Sketches by GUERRA, M., DINARDI, C. and ROCHA, V.

The image below presents the raw materials selected to be worked with. In addition to feldspar, tourmaline gravel and natural pigments are found in the region. The small rough tourmaline is abundant because its processing in traditional ways is not economically viable. The gemstone with this quality standard has a low unit value due to its very dark colors, reduced sizes and presence of many inclusions, so the cost of cutting would be much higher than the value of a final cut stone.

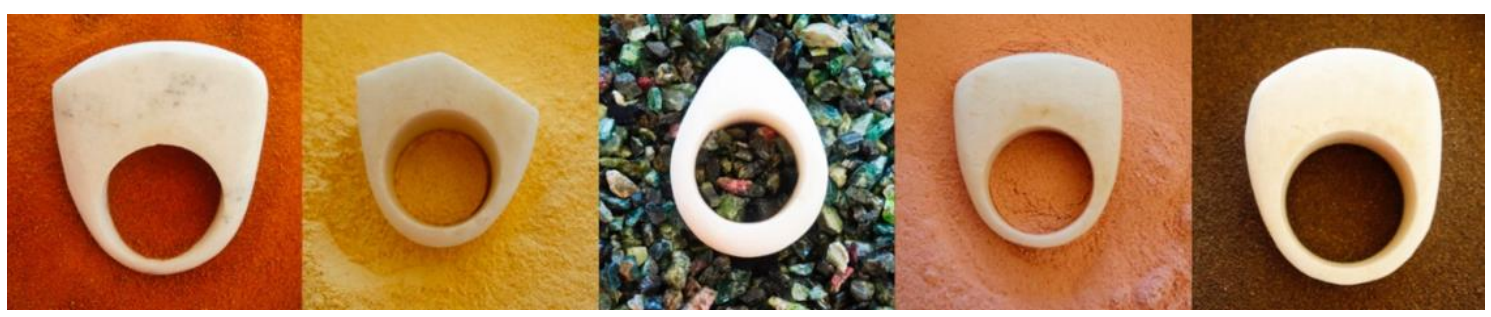

Figure 5: Natural pigments from the region, feldspar and tourmaline gravel. Photo: Raquel Canaan.

Feldspar, the main constituent of igneous rocks and raw material for the manufacture of porcelain in the white ceramic industry, is loaded onto trucks near the mines, to be sold for a few dollars per metric ton to companies in the south of the country. The lands in the region form the basis for the mineral pigments that decorate the surface of the products and are collected in 
several places near the city of Coronel Murta, such as in the Palmeiras, Miguel Pedro and Chapada digs.

Based on the final concept, the production unit started its production, assisted and guided by CEDGEM's master craftsmen and researchers. The shapes of the rings and pendants had the simplicity of rolled pebbles and were produced by apprentices who quickly become able to reproduce them, as they have vivid memories of the gravel they step on at the end of the afternoon, on the banks of the Jequitinhonha River (MOL, 2019).

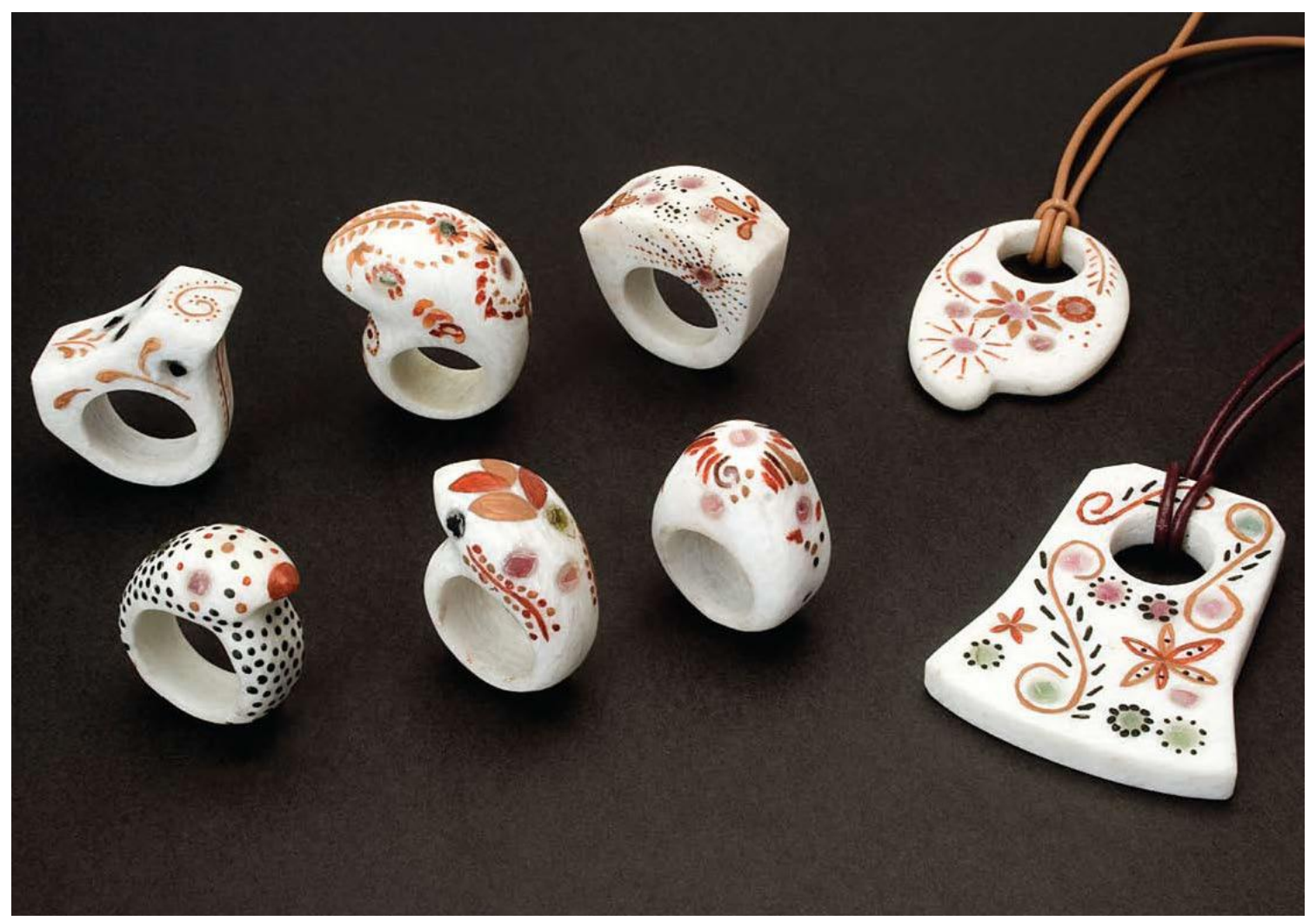

Figure 6: Prototypes of Itaporarte line products. Photo: Toninho Mattos.

The last step in construction is painting the surface with the region's natural pigments, collected in different parts of the city. The earthy yellow, brown and red minerals are then separately ground, refined by macerating and sieving, making them as fine as possible, and turning them into pigments to make up a suspension in water. These "paints" are carefully applied with fine brushes, forming the surface decoration used to illustrate the aesthetic references of Vale do Jequitinhonha itself. After each sample dries out, non-mineral materials as well as clods that do not fall apart are removed and then fixed with cold curing epoxy resin. Then, the pieces are finished to be polished.

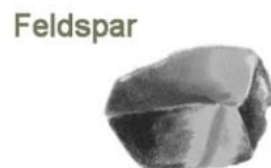

Pigments

Tourmaline Es

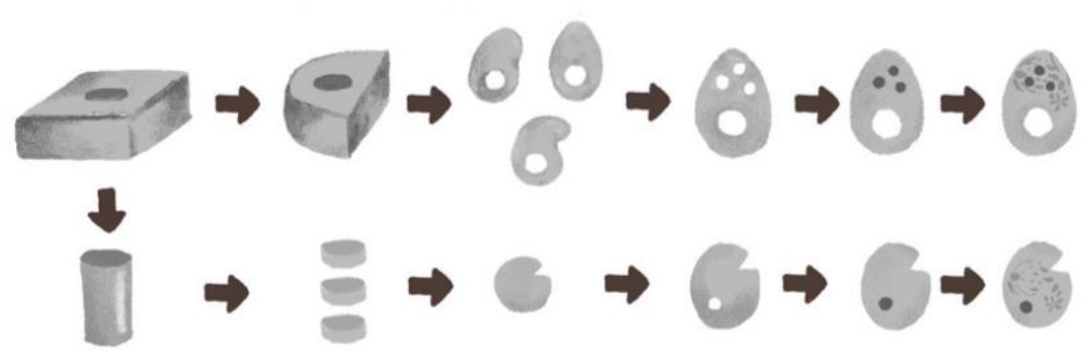

Figure 8: Synthesis of the productive steps of gem cutting and surface treatment.

The project needed also had to include educational and technological actions. In this process, design was the element of integration due to its ability to promote interactions and collaborative 
experiences in the productive environment, acting in the sharing of theoretical and practical knowledge, integrating related scientific and tacit knowledge.

A final project was conceived in 2010 , adding production standardization, guided by the development goals of a new product line, defining formal and production standards to be recorded in a standardization and procedures manual that would guide further development of the products.

\section{The sustainable aspects of Itaporarte products of contemporary mineral craft}

The mineral handicraft proposal from the Itaporarte laboratory in Coronel Murta presents a design with strong identity and aesthetic appeal, respecting in its production process relationships of sustainability in several aspects. These were illustrated by CANAAN (2012) in a study that organized the project's outcomes in the classic attributes of cultural, environmental, economic and social responsibility.

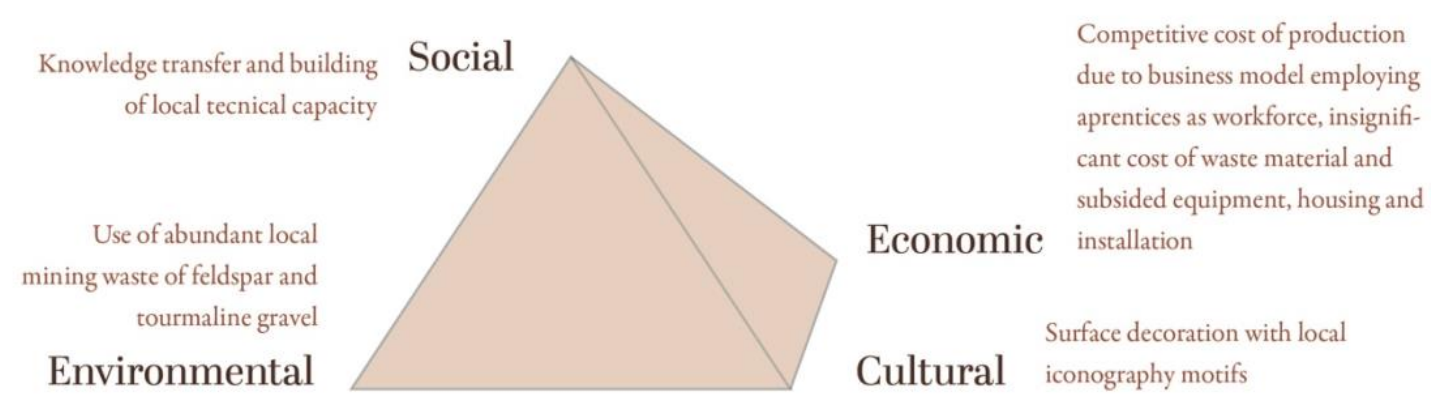

Figure 9: Sustainability initiatives present in the project. Source: Canaan, 2012.

The social aspect relates to the whole strategy of the project, that was about installing a lowcomplexity mini productive arrangement aimed at the development of integrated actions, their demands and assumptions within the dynamics of local systems. The initiative sought to value the practices, techniques and processes associated with the competencies and skills of local groups, by evaluating their interests, conflicts and contradictions, as well as technical possibilities and local capacity already installed. During these actions by the teams composed of technical consultants, professors, scholarship holders and interns, it was confirmed that, far beyond the potential use of discarded material, there was a human potential with great receptiveness to transformation though added value. On top of that potential, technical and educational activities would contribute to the development of a process that would be strengthened whenever replicated to new groups, highlighting the social aspect of the initiative (TEIXEIRA, 2020).

Capacity building and training are ongoing processes, which should be developed permanently in the region by local technicians, in parallel with the development and testing of the products. The first group to be trained involved thirty-five young persons at different lapidary knowledge levels, including basic, medium and more advanced skills.

The teaching methodology was based on the practice of production procedures, including the theory necessary for knowledge of the techniques and materials used in production. All training participants had the opportunity to know and experience each stage of production and as they identified themselves with one or more tasks, they improved on them, in order to form groups of skills necessary for the production process. This group organization model allowed all the people interested in the training to have, within the group, a role, among those necessary for the production of the proposed craft. To date, thirty-five people have been trained and trained in the laboratory, who can produce an average of two hundred pieces per month, such as the line of rings that is part of the first collection and others already designed that include lines of jewelry, souvenirs and decorative objects. The projects work on the transfer of knowledge and technology generated at CEDGEM, involving scholarship students and teachers in the technological training of people in the community in the production of artifacts in mineral 
handicrafts, forming the apex of the project's social sustainability initiatives.
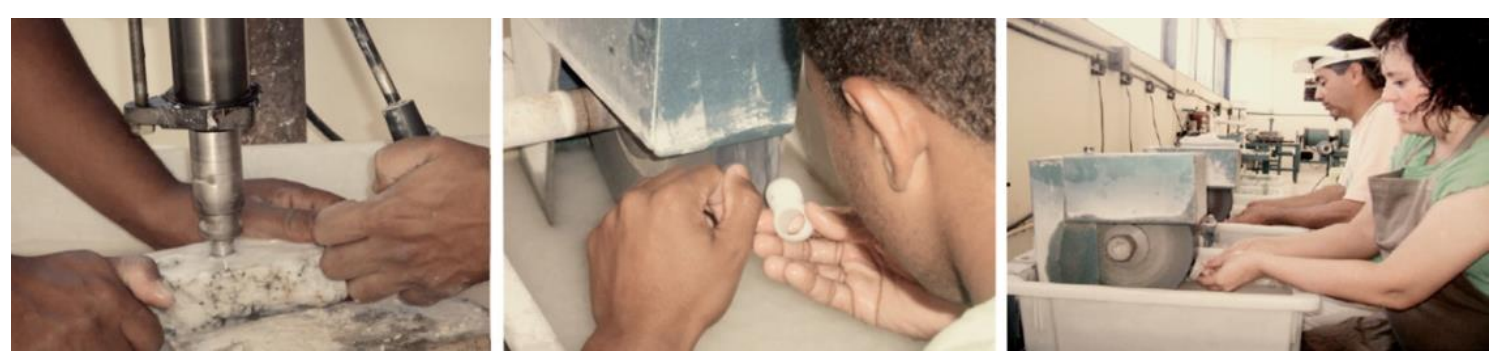

Figure 10: Local training for the production of mineral handicrafts: the training procedures for production were organized in production stages from the selection of raw material, through cutting, shaping, inclusion of accessory materials and final finishing, allowing the apprentice to practice all production stages. Photos: Mara Guerra.

The project can be thus configured as a social innovation, where new opportunities were created from a problem in the sector, with the support of local agents and the support of the UEMG team, by training and employing available young manpower.

It added value not only to the human resources available in the region but also to its local culture. This cultural aspect started out by developing products aligned to the region's identity and carrying universal quality. During the project, visits and meetings between researchers and residents of the region contributed to their integration and to the collection of information, which served as a subsidy for the design of more feasible product models aligned with such local aspects, which were to be incorporated into the products.

From the initial proposal, the products were refined to be crafted with low complexity techniques, to allow the quick learning of lapidary in the production unit's equipment that was installed by the University, and to make possible subsequent formal contributions from producers, expanding and reinforcing the iconographic aspects and identities of the region. The drawings to be painted on the pieces, made by volunteers trained in painting workshops, were initially developed inspired by the iconography the Jequitinhonha Valley pottery, a recognized cultural characteristic of the region. As they became skilled in these paintings, however, it was possible to identify personal preferences when selecting drawing motifs, what allowed the group to identify individual contribution.

On the environmental side, the products are predominately built with local raw material, which is widely available at a negligible cost, as the pink or green tourmalines gravel used is collected manually in waste piles around the famous Barra de Salinas and Lorena Mines. The feldspar coming from Palmeiras Dig is found in abundance in the region, which, due to its commercial value being sold in tonnes, is supplied at no cost by the Prospectors Association. The paintings on the surfaces are made with minerals from the region, collected within a radius of 10 kilometers by the Laboratory participants.

This recycling of discarded material, that doesn't require additional mining to be obtained and would otherwise be waste, is an obvious environmental gain of the project and its material basis for the creation of value. Exploiting a non-renewable resource such as gemstones is a unique opportunity, and a huge responsibility because, unlike other materials that can be rebuild or replanted, these gemstones were produced by nature in a few unique events, rarely sparse across the planet, were not destroyed over millions of years of weathering and are hardly found and extracted today.

The lapidary techniques used there made possible to associate minerals that otherwise would not have an economically viable processing. The innovation of the lapidary proposal is to promote a harmonic combination of materials and surface treatments not obvious at first glance. Cutting design is the development of new models that observe both aesthetic and productive aspects. The process involves objective analysis such as the good use of raw material in relation to the final formats, and the choice of appropriate techniques to enable the production of new products. Furthermore, in the lapidary design factors such as the perception of the material through its brightness, color and hardness are also considered. The interaction of all these factors can go unnoticed by the layperson, who often focuses exclusively on the formal aspects of the product (MOL, 2009). 
The support in supplying the materials by the Prospector's Union and the housing, maintenance and financial aid to the local technicians provided by the City Hall also contributed to the low start up investment and financial equilibrium of the endeavor. These zero costs can be coupled with free labor, because its production is done by apprentices who are learning a craft but at the same time are capable of producing a product that was designed to be rustic, mimicking pebbles from the beloved river that names their territory.

\section{Epilogue: Perspectives}

Throughout the many years in development of the Itaporarte studies, it was possible to confirm real possibilities for the insertion of design concepts related to the territory as potential value addition within the productive chain of gems and jewelry. The sector's value chain is still little explored due to its complexity, which, on the other hand, expands the possibilities of inserting design at its various levels, as described by the project's leader TEIXEIRA (2021).

About the possibility of adding value to materials of low commercial value through the addition of design thinking and other methods, it was concluded that it can result in competitive products, which can bring bigger returns to the population of small production units. The use of intelligent lapidary techniques allowed for the economic use of these materials in a simplified production model, to be made by apprentices, that contributed to the professional qualification of young people with few opportunities for insertion in the labor market. The improvement of these techniques and processes generated new products which had the regional identity expressed in the formal aesthetics associated with the ceramics of Vale do Jequitinhonha, easy to identify and recognize.

Other relevant aspects where observed in the practice, such as the understanding of the need, within a project, to know the history, culture, people and vocations of individuals and their communities, in addition to the importance of carrying it out properly. The partnership between different actors in the community is a factor in the project's self-sustainability, and should be participatory, rather than welfare or paternalistic.

The total adherence of participants to the course activities revealed a latent demand for qualification in the sector which, associated with the idea of developing handcrafted products, shaped the environment that lead to the installation of the productive unit in that city.

Knowing and recognizing the culture of the region in the middle and through the eyes of the community itself was crucial to identify the limits and potential that would give materiality to the project. The name ITAPORARTE itself was a natural consequence of an integrative process. It was born from the collective inspiration of the students during the course, stimulated by the interaction of different people in a brainstorming activity. The action of art in stone, represented by the name, also endorsed the possibility of making use of the discarded mineral wealth that flourished in the region and which the local community took little advantage of. The idea/challenge was to transform through design a subaltern material into products with high identity content, reactivating aspects of the mineral brand and local culture. The design would thus be fulfilling one of its principles, which is to contribute to the perception of the product as a cultural manifestation of the productive community in the region where it originated.

Multiple developments of the possibilities pointed out in the construct of the value chain were identified, to be used in future works related to the sector, in which small sustainable practices can be applied as a solution within a possible scenario. Local productive clusters are not invented. They already exist, need to be identified and supported by effective projects that put diverse actors in the same line of work, such as entrepreneurs, governments and educational institutions. Likewise, arrangements and territories are not the same, so it is important to highlight as one of the conclusions about this work, that it is not possible to establish very strict standards in the execution of a design management project. Each project has its specificities and it is necessary to understand the context, the network of actors that is formed, the vocations, potentials and significant aspects that make up the local history in order to seek adequate solutions to the demands in different realities. A more strategic, long-term coordination is needed, and management through design can be the link between the various areas of the cluster, guiding its objectives and configuring itself as a critical success factor, and this takes place through multidisciplinary work (TEIXEIRA, 2021). 
In Brazil, Minas Gerais and, specifically, in the Jequitinhonha Valley, there are many project proposals with the objective of improving the quality of life of the people who live there, developing new activities, and making the territory more dynamic. This is because in the region it is very common for local people to evade, in order to seek a "better life", study, work, in other places. On the other hand, an intrinsic characteristic of Jequitinhonha Valley region is the discontinuity of the actions that begin there. Many projects are unsustainable and end before completion. The population of northeastern Minas Gerais state, due to their historical roots and past experiences, became disbelieving and distrustful and this is noticeable in the field work.

Despite the positive results achieved by the project, the political changes in the region, the lack of resources from Coronel Murta's City Hall and the University itself were obstacles to its continuity and to fully meeting the expectations of the team and the local population. For CEDGEM, it is worth emphasizing that the project was important in confirming its culture of building knowledge considering its transfer and applicability to real situations. For professionals and researchers, the experiences and experiments in the Vale do Jequitinhonha region indicate that actions in cooperation networks can contribute to a real transformation in the productive and academic sectors. The dynamization and improvement of these relationships can open innovative perspectives for both. However, without a public policy to support their interaction, they will continue to have a low level of complementarity, at the expense of both sectors.

\section{Final thoughts}

When the products began to be produced on a large scale, local young people became interested in the Project and started to work voluntarily at the Laboratory, in search of an opportunity for training and specialization. At this stage, it was possible to see the city "embracing" the Project, as both the local community and supporters such as the City Hall and the Prospectors Union recognized the products as typical of the Region, reflecting the local identity and material wealth.

As a result of this involvement, in 2012 a Term of Commitment was signed by the Municipality of Coronel Murta with the State University of Minas Gerais and the Prospectors Union of Coronel Murta, where the community undertook, for ten years, to support the actions of the Itaporarte Laboratory, the assignment of the space where it worked and the contract of three extension workers in the region to work in the laboratory.

A Best Practices Award in Mineral Clusters ${ }^{2}$ granted to the Itaporarte Project in 2013 confirmed the potential of this initiative, and it recognized its proven methods carried out within that production chain of the mineral sector, considered a model of best practices involving managerial and technological procedures, with environmental, financial and market gains or contributions to the sustainability of a business model.

From the project's results, one can conclude that small educational and technological actions can contribute to a real and positive social, economic and environmental transformation and that these small actions can trigger a gradual process of development to be reproduced in other communities.

Despite some problems encountered in the confrontation with the local reality, such as those related to reconciling distance, time and infrastructure, which delayed and hindered the development of the project, an important point to be highlighted as a perspective of continuity and deployment of the projects is adherence of the community. The local understanding of the importance of design in the construction and differentiation of the product, not only as an aesthetic, but as a value addition, was a determining factor for the acceptance of the project, as bonds of trust were created with the population, who understood the importance of their participation in the actions of the project aimed at them. This adhesion is configured as a very significant point to solve the problem of projects without continuity, as they are a sustainability factor for the developed actions.

\footnotetext{
2 The Brazilian Information Network on Mineral-Based Local Productive Arrangements (RedeAPLmineral) is responsible for the dissemination of information and best practices in the production chain of the mineral sector, comprising the processes of extraction, processing, and mineral transformation organized in mineral base clusters. Initiative of the Brazilian Ministries of Mines \& Energy and Science \&Technology.
} 


\section{Acknowledgment}

The authors wish to thank FAPEMIG, the Foundation for Research Support of the State of Minas Gerais - for their support in the research that led to the implementation of the UEMG/FAPEMIG Itaporarte Laboratory of Design and Mineral Craft.

We also thank the CAPES-PROAP Graduate Support Program, for providing a grant for the dissemination of the Itaporarte project in a book from which this article in English was derived.

\section{References}

CANAAN, Raquel P. (org). Itaporarte: Estudo do design aplicado ao setor de gemas e joias com vistas à inovação social e valorização do território do Vale do Jequitinhonha. Belo Horizonte: edição do autor, 2020. 60p. ISBN: 978-65-00-01479-2

CANAAN, Raquel P. Gemas e Joias: a gestão pelo design aplicada à cadeia de valor de Arranjos Produtivos Locais, Dissertação (Mestrado em Design). PPGD-UEMG, 2013.

CORNEJO, C; BARTORELLI, A.; Minerais e Pedras Preciosas do Brasil. São Paulo: Solaris Edições Culturais, 2010.

MOL, Adriano A. Lapidary Design Manual. Brazilian Institute of Gems and Precious Metals (IBGM), Brasília, 2009.

MOL, Adriano A. Adding value to material resources. in: CANAAN, Raquel P. (org). Itaporarte: Estudo do design aplicado ao setor de gemas e joias com vistas à inovação social e valorização do território do Vale do Jequitinhonha. Belo Horizonte: edição do autor, 2020.

TEIXEIRA, M. Bernadete S. Installation Project of laboratories to expand research in the product development area of the design school's gem and jewelry design center. FAPEMIG Special Research Project. State University of Minas Gerais, 2006.

TEIXEIRA, M. Bernadete S. Afirmação da capacidade tecnológica das pequenas aglomerações produtivas: diretrizes metodológicas guiadas pelo Design. Tese (Doutorado em Design). PPGDUEMG, 2021. 